\title{
Establishment of new wintering areas in herring co-occurs with peaks in the 'first time/repeat spawner' ratio
}

\author{
Geir Huse $^{1, *}$, Anders Fernö ${ }^{1,2}$, Jens Christian Holst ${ }^{1}$ \\ ${ }^{1}$ Institute of Marine Research, 5817 Bergen, Norway \\ ${ }^{2}$ Department of Biology, University of Bergen, 5020 Bergen, Norway
}

\begin{abstract}
Norwegian spring spawning (NSS) herring migrate to wintering areas in late summer and remain there for about 5 mo in dense aggregations. First-time spawning cohorts typically adopt the wintering area of the spawning stock. However, over the last $50 \mathrm{yr}$ the NSS herring stock has occupied 7 discrete wintering grounds, spanning from the high seas to narrow fjords, which shows that there is considerable plasticity in choice of wintering area. We show that 5 cases of establishment of new wintering areas take place when abundant first-time spawning cohorts take up the adult migration pattern. The ratio in abundance between age 4 and age $5+$ herring is on average 14 in the years when new wintering areas are established compared to 0.3 in years without changes. The wintering areas vary greatly with regards to temperature and distance to the feeding and spawning grounds, features that heavily affect energy expenditure during wintering and migration. Rather than being strictly optimized, the establishment of new wintering areas seems to be governed by general school cohesion mechanisms when naïve first-time spawners flood the population and the social learning process is disrupted.
\end{abstract}

KEY WORDS: Norwegian spring spawning herring $\cdot$ Wintering area $\cdot$ Demography $\cdot$ Schooling · Migration Resale or republication not permitted without written consent of the publisher

\section{INTRODUCTION}

\section{Fish migrations}

Many fish populations undertake extensive migrations that can encompass billions of individuals. The life cycle of migratory fishes typically comprises migrations between spawning, wintering and feeding areas (Harden Jones 1968), enabled through compass orientation systems, for example using geomagnetic fields (Lohmann \& Lohmann 1996, Walker et al. 1997). Migrations enable exploitation of temporal and spatial variability in the environment, counter larval advection and ensure geographic persistence of the stock (Harden Jones 1968).

Migrations are often seen as an individual fitnessmaximizing process (Sutherland 1996). In many cases this assumption is valid, in particular where single individuals make decisions based solely on seasonal changes in the environment, on their state (Mangel \& Clark 1988) or density of conspecifics (Fretwell \& Lucas 1969). But often decisions are not made by independent individuals, but by groups of individuals that interact socially (see review by Brown \& Laland 2003). Schooling fishes, such as herring, spend the majority of their life time in a school. This implies that the behaviours of individuals are constrained by what others are doing and that individual decisions about where to move become more complex than in the case of individual fitness maximization. It has been shown in field and laboratory experiments that a few experienced individuals can lead a group of naïve fish to feeding areas (Helfman \& Schultz 1984, Reebs 2000). Simulation experiments have further shown that individuals that behave more independently of the school can be particularly influential on the school behaviour (Romey 1996). Some individuals can thus have a strong influence on the collective behaviour of a group and exert 
leadership. The degree to which individuals will exert leadership is often related to their knowledge level or motivation. For example, food-deprived roach Rutilus rutilus appear more often in front of a school than wellfed individuals (Krause et al. 1992). However, it is probably costly to consistently lead a school both in terms of predation risk and energy expenditure, and in the long run individuals will have to trade off their behaviour to accommodate the rest of the school. For example, post-spawning observations of individual herring with fully developed or ripe ovaries in schools that are moving away from the spawning ground (A. Slotte pers. comm.) indicate that collective behaviours can override the strong individual urge to spawn. Thus, the school association has positive effects, e.g. related to increased foraging (Pitcher et al. 1982) and reduced mortality (Pitcher \& Parrish 1993), but can also have negative effects, e.g. the tyranny of collectivity.

\section{Changes in wintering area of Norwegian spring spawning herring}

The Norwegian spring spawning (NSS) herring Clupea harengus L. stock follows a classic migration pattern (Harden Jones 1968) and spends the winter in dense concentrations without feeding, awaiting and preparing for the commencement of spawning in spring and the subsequent return of plankton to the surface waters. The adult part of the stock mostly winters together in one area. There have been substantial changes in the location of the wintering area of NSS herring since the 1950s as illustrated in Fig. 1. During the 1950s and for an unknown period before, the wintering area was to the east of Iceland (Area 1, Fig. 1; Devold 1968, Dragesund et al. 1997). However, a large fraction of the 1959 year class established a separate wintering area in 1963 south of Bear Island, which was utilized for $3 \mathrm{yr}$ before this component joined the rest of the stock and adopted their migration pattern (Area 2, Fig. 1; Devold 1968, Dragesund et al. 1997). When the 1969 year class matured, it initiated 2 separate wintering areas, in the fjords of Lofoten and Møre, respectively (Area 3, Fig. 1; Holst et al. 2002). The 1983 year class started wintering in Tysfjorden and Ofotfjorden in 1987 (Area 4, Fig. 1; Røttingen 1990, Dragesund et al. 1997). The 1991 and 1992 year classes started to winter in Vestfjorden, in addition to Tysfjorden and Ofotfjorden, in 1995 (Area 5, Fig. 1; Foote et al. 1996, 1997).
Although Areas 4 and 5 (Tysfjord/Ofotfjord and Vestfjord, Fig. 1) are close together, Area 5 was not utilized as a wintering area prior to the autumn of 1995, when new recruits of the 1991 and 1992 year classes joined the spawning stock. In 2002, when the 1998 and 1999 year classes recruited to the adult stock, a new wintering area was initiated north of Vesterålen (Area 6, Fig. 1). Presently this is the main wintering area of NSS herring, and the fjords are deserted (measured by the Institute of Marine Research [IMR], Bergen in winter 2007-2008).

Since NSS herring spend such a long period of time in one location, the choice of the wintering area seems critical. In the absence of feeding, important factors to consider are survival and energy costs, and it seems

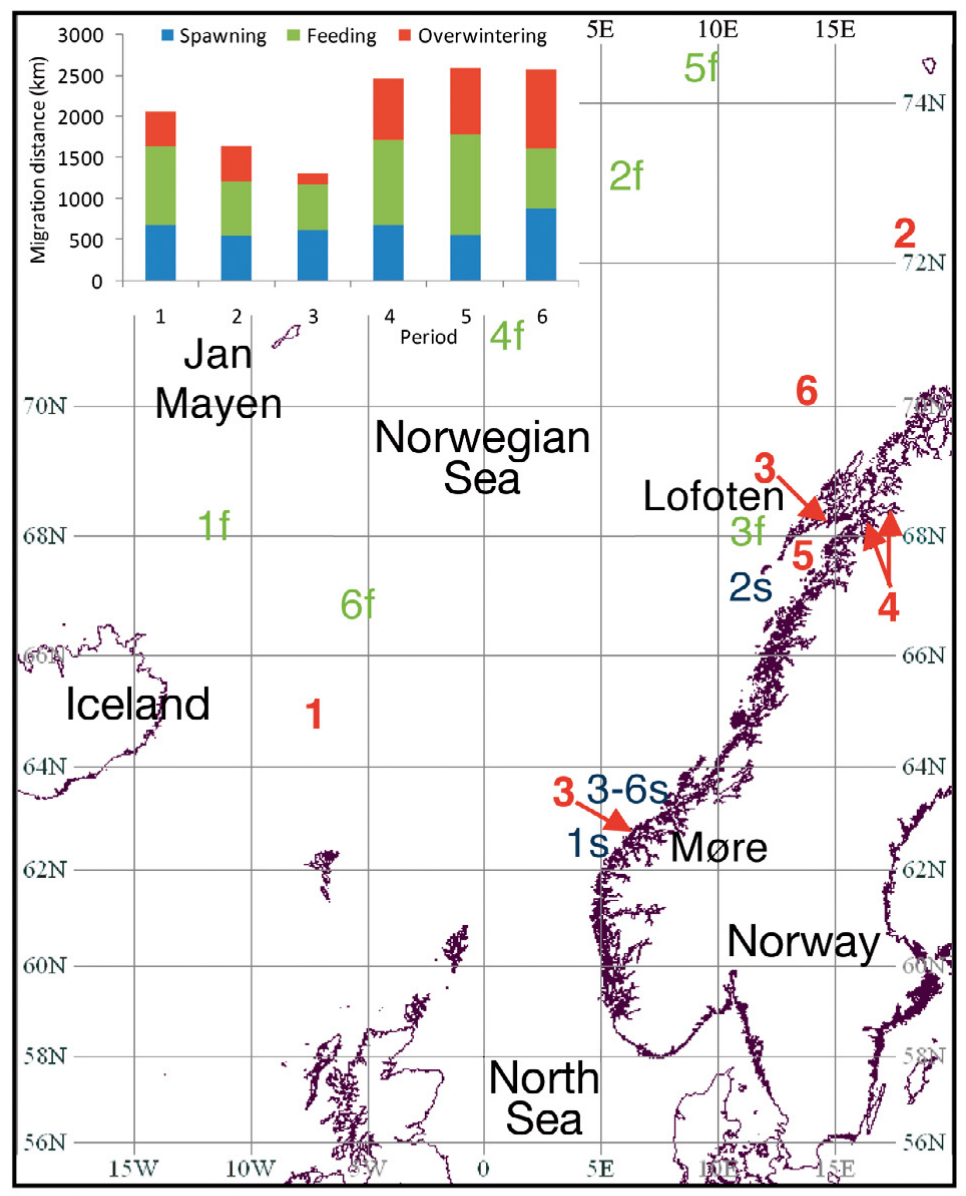

Fig. 1. Distribution of wintering (red), spawning (blue, s) and feeding (green, f) areas of Norwegian spring spawning herring during the last 50 yr (location, main period). (1) Iceland 1952-1956, (2) Bear Island 1965, (3) Lofoten Islands 1973-1986, (4) Ofotfjorden-Tysfjord 1988-1994, (5) Vestfjorden area 1995-2001, (6) Vesterålen 2002-2005. The numbers indicate the chronology of wintering distributions. Inset: estimated displacement of the spawning, feeding and wintering migrations for each period. Areas 1-3 were taken from Dragesund et al. (1997), Area 4 from ICES (1997), Area 5 from Jacobsen et al. (2002) and Area 6 from recent surveys (Institute of Marine Research [IMR] unpubl. data) 
plausible that the herring will optimise the choice of wintering habitat with regards to these factors. However, the Darwinian fitness of an individual is defined in terms of its contribution to the future gene pool of the population relative to that of other individuals (Roff 1992, Stearns 1992, Krebs \& Davies 1997). It could therefore be argued that the conditions of the wintering area affect all the individuals of the population equally and therefore have little effect on Darwinian fitness. Thus, in theory, any wintering area could prevail as long as it permits the herring to spawn along the Norwegian coast in spring. In this case the prediction is that it is unlikely that there will be a strong selection for any particular wintering habitat.

\section{Social learning and herring migrations}

There is presently little consensus about the causes behind the changes in wintering area. Herring migrations have typically been explained in terms of climate or predator-prey interactions (Dragesund et al. 1997, Fernö et al. 1998, Toresen \& Østvedt 2000, Corten 2001a, Holst et al. 2004). However, there is increasing support for the theory that herring migrations are influenced by social learning (Røttingen 1992, McQuinn 1997, Fernö et al. 1998, Misund et al. 1998, Slotte 2001, Huse et al. 2002), and the evidence for this has been reviewed by Corten (2001b). According to the adopted migrant hypothesis (McQuinn 1997), young herring cohorts learn migration patterns from schooling with older individuals, and maintain the adopted tradition in subsequent years, a so-called vertical transmission of social learning (Brown \& Laland 2003). If herring migrations are influenced by social learning between individuals, schools and cohorts, the abrupt changes in migration pattern could be a consequence of absence of social learning (Corten 2001b). Since social learning requires interaction between experienced and naïve individuals, lack of spatial overlap could disrupt the learning. But the learning process could also be disrupted if there are too few experienced individuals to guide the naïve ones (Corten 2001b). The latter hypothesis was investigated in a simulation study (Huse et al. 2002) using a school consisting of naïve (recruits) and experienced individuals. These simulations suggested that the abundance ratio of naïve to experienced individuals, or recruits to older herring, is a key parameter, and if the proportion of experienced individuals is too low they will not exert leadership on naïve individuals (Huse et al. 2002). Similarly, it was argued that some recruiting year classes of NSS herring are too abundant to allow guidance from older fish, a process termed numerical domination. While this mechanism was discussed by focusing on the distribution pattern of some abundant herring cohorts, Huse et al. (2002) did not make a quantitative analysis of correspondence between demographic and geographic changes of the stock. Moreover, the adaptive consequences for the herring of the changes in wintering area, related to energy expenditure, which depends on temperature and migration distances to the spawning and feeding areas, were not evaluated.

The objectives of the present study were to quantify the ratio of recruit to repeat spawners for NSS herring over the last $60 \mathrm{yr}$, relate this ratio to changes in migration pattern and discuss this in relation to alternative hypotheses for the changes in wintering area. Furthermore, we evaluated the consequences of changes in wintering area for wintering habitat and migration distance.

\section{MATERIALS AND METHODS}

The data on herring numbers and weight at age from the period 1950-2007 were taken from the ICES report of the Working Group on Northern Pelagic and Blue Whiting (ICES 2007). The numbers-at-age data were generated by virtual population analysis based on a combination of landings data and scientific survey information (ICES 2007). The age at which herring matures varies between individuals and cohorts (Toresen \& Østvedt 2000). The herring cohorts generally leave the nursery grounds along the Norwegian coast or in the Barents Sea (Holst \& Slotte 1998) at age 3 to 5 and adopt an adult migration pattern associated with feeding migrations into the Norwegian Sea (Dragesund et al. 1997). Here we used age 4 as the age for recruitment to the adult migration pattern, since in general this is the age when most individuals in a cohort mature (Toresen \& Østvedt 2000).

The locations for wintering, spawning and feeding (Fig. 1) were taken from literature presentations of maps of herring migration and distribution (Devold 1968, Røttingen 1990, Dragesund et al. 1997, Misund et al. 1997, Fernö et al. 1998, Holst et al. 2002). During the spawning and feeding period, herring are spread out over rather large areas along the Norwegian coast and in the Norwegian Sea. This makes a point estimate of position imprecise in relation to individual migration distance, but can provide rough estimates on the overall displacement of the stock. We therefore established centers of mass through visual inspection of different maps of herring distribution. These positions were used to estimate migration distance using the Haversine trigonometric formula (Box 1; Sinnott 1984). Wintering temperature for NSS herring during different periods and locations (Fig. 1) was estimated from data held at the IMR, Bergen. An overview of the CTD data used to calculate the temperature is given in Table 1. 
Box 1. Haversine trigonometric formula

Presuming a spherical Earth with radius $R$ (see below), and the locations of the 2 points in spherical coordinates (longitude and latitude) are lon1, lat1 and lon2, lat2, then the Haversine formula (Sinnott 1984):

dlon $=$ lon $2-\operatorname{lon} 1$

dlat $=$ lat $2-$ lat 1

$a=\sin ^{2}($ dlat $/ 2)+\cos ($ lat 1$) \times \cos ($ lat 2$) \times \sin ^{2}(d$ lon $/ 2)$

$C=2 \times \arcsin \{\min [1, \operatorname{sqrt}(a)]\}$

$d=R \times C$

will give mathematically and computationally exact results for distance between geographical positions. The intermediate result $c$ is the great circle distance in radians. The great circle distance $d$ will be in the same units as $R$.

\section{RESULTS}

The NSS herring stock has gone through major changes in abundance over the last $50 \mathrm{yr}$, and now has a record high abundance after being in a collapsed state for $20 \mathrm{yr}$ during the late 1960s to the mid-1980s (Fig. 2A). All the initiations of new wintering areas in NSS herring co-occurred with the recruitment of abundant year classes to the spawning stock. This is seen as peaks in the ratio of the number of young (age 4) to old (age 5+) herring in Fig. 2A. This ratio is on average about 14 (arithmetic mean $\pm \mathrm{SE}=13.84 \pm 9.88$, median $=2.05, \mathrm{n}=5$ ) in the years when changes in wintering area occurred (lines 2 to 6 in Fig. 2A) compared to an average of about 0.3 (arithmetic mean $\pm \mathrm{SE}$ $=0.34 \pm 0.12$, median $=0.1, \mathrm{n}=54$ ) in years when no changes were reported. The corresponding geometric means are 4.57 and 0.11 . The ratio between the means is similar to the arithmetic means, although the magnitude is lower. The differences in the ratios were significant (Mann-Whitney $U$-test, $\mathrm{p}<0.01$ ). The establishment of new wintering areas is illustrated by the vertical lines and the numbers refer to the location of the new wintering area (Figs. $1 \& 2 \mathrm{a}$ ).

Swimming speed generally scales positively with fish body size (Videler 1993), and since abundant cohorts often have a lower than average weight at age (Toresen \& Østvedt 2000), we investigated whether there was a similar pattern in the ratio of recruit to repeat spawners in size at age as seen for abundance. There was no consistent characteristic in the size ratio or in the size of the recruits associated with the reported changes in wintering area (Fig. 2B). Distribution of fish is often related to climatic variability, for example in temperature. However, we found no pattern between temperature (in the Russian Kola section; see Tereshchenko 1996) and the changes in wintering area (Fig. 2C), although herring recruitment was positively correlated with temperature (Sæetre et al. 2002).

Nevertheless, the wintering areas utilized by NSS herring varied greatly with respect to temperature conditions (Fig. 3, Table 1), and the areas used in the 1950s were much colder than the areas presently used. The variation in temperature at the utilised locations (Fig. 3) shows that the herring do not have narrowly defined thermal criteria for wintering habitat. Furthermore, the distances between wintering, spawning and feeding areas have varied strikingly over the last $60 \mathrm{yr}$ (Fig. 1, inset). In recent years the older members of the NSS herring population have been feeding in the waters east of Iceland, wintering north of Vesterålen (Area 6, Fig. 1) and spawning at Møre, and undertaking migrations covering about $2700 \mathrm{~km}$. In the 1950s, when the herring wintered just southeast of the feeding grounds, the corresponding migration was about $2100 \mathrm{~km}$. During the stock collapse in the 1970s, the migration distance was only about $1300 \mathrm{~km}$, and even smaller than this for parts of the stock at that time (Holst et al. 2002). Thus, although the estimates of migration displacement are rather imprecise, they illustrate that the changes in migration distances for the stock have been substantial. The shortest migration displacement (Area 3, Fig. 1) is also associated with the highest weight at age (Fig. 4), but this cooccurs with a very low stock abundance and it might be a density-dependent effect. All in all this illustrates that NSS herring are highly plastic with regards to wintering habitat and migration pattern.

Table 1. Locations of Conductivity-Temperature-Density (CTD) stations used to estimate temperature in wintering areas (Figs. $1 \& 3$ ). N: number of stations used in calculating the temperature

\begin{tabular}{|c|c|c|c|c|c|c|c|c|}
\hline Location no. & Min. & $\begin{array}{l}\text { Latitude } \\
\text { Max. }\end{array}$ & $\overline{\text { Mean }}$ & Min. & $\begin{array}{l}\text { ongitude } \\
\text { Max. }\end{array}$ & Mean & $\begin{array}{c}\text { Median day } \\
\text { of year }\end{array}$ & $\mathrm{N}$ \\
\hline 1 & 64.0 & 66.0 & 64.55 & -9.0 & -7.0 & -8.1 & 343 & 11 \\
\hline 2 & 71.0 & 74.0 & 72.23 & 16.0 & 20.0 & 18.6 & 319 & 9 \\
\hline 3 & 67.5 & 68.5 & 67.81 & 13.0 & 15.0 & 13.8 & 305 & 2 \\
\hline 4 & 67.5 & 68.5 & 68.12 & 15.0 & 18.0 & 16.3 & 324 & 98 \\
\hline 5 & 67.0 & 68.5 & 67.55 & 12.0 & 15.0 & 13.9 & 300 & 19 \\
\hline 6 & 69.5 & 71.5 & 70.53 & 15.0 & 17.0 & 16.0 & 341 & 20 \\
\hline
\end{tabular}




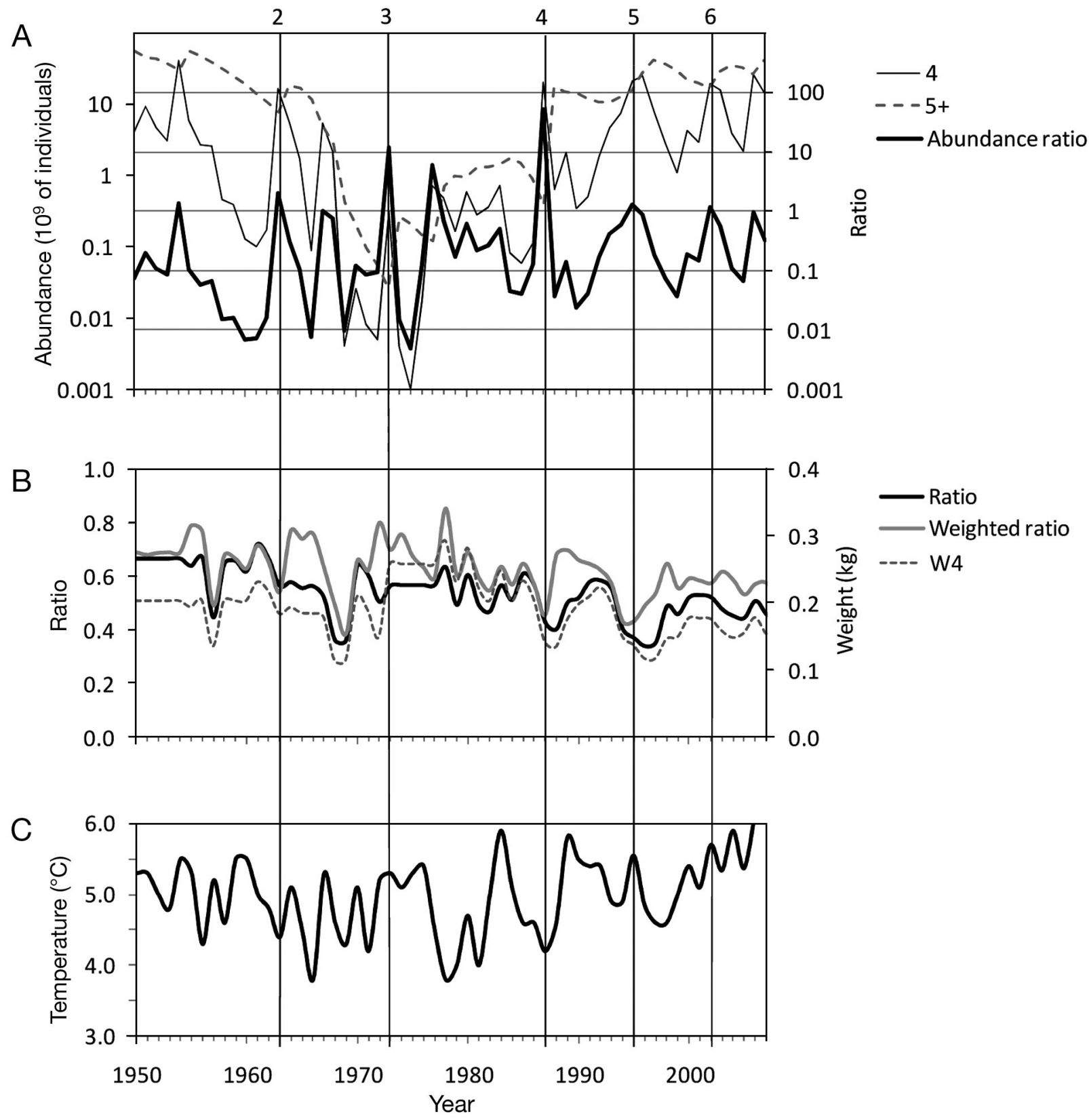

Fig. 2. Clupea harengus. (A) Abundance of Norwegian spring spawning (NSS) herring at age 4 and 5+ and their ratio (N4/N5+) (ICES 2007); (B) weight of age 4 NSS herring (W4) and the ratio of weight of age 4 to average weight of age 5+ NSS herring (ICES 2007 ), both for a simple average weight of $5+$ (ratio) and a weighted average by number per age (weighted ratio); (C) temperature from September in the Kola section (Tereshchenko 1996). Vertical lines indicate known changes in the wintering area; numbers refer to the areas in Fig. 1

\section{DISCUSSION}

\section{Are changes in wintering area related to demography or geography?}

The establishment of new wintering areas of NSS herring co-occurs with the recruitment of relatively strong year classes to the spawning stock. This sug- gests that the relative scarcity of older herring is the key factor in breaking traditions (Corten 2001b) and establishing new wintering areas for the NSS herring stock. These changes have been shown to substantially affect the migration dynamics of the stock.

We have identified 5 major changes in the wintering area that are documented in the literature over the period 1950 to 2008. There is anecdotal evidence for 


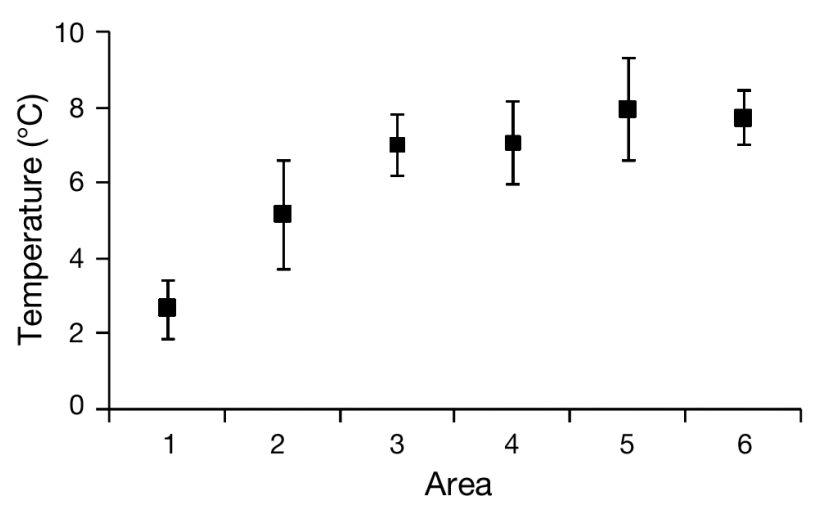

Fig. 3. Average $( \pm \mathrm{SD})$ temperature at 0 to $200 \mathrm{~m}$ depth in wintering areas of Norwegian spring spawning herring. Area numbers refer to wintering areas in Fig. 1. Data (see Table 1) were taken from the temperature database at the Institute of Marine Research, Bergen

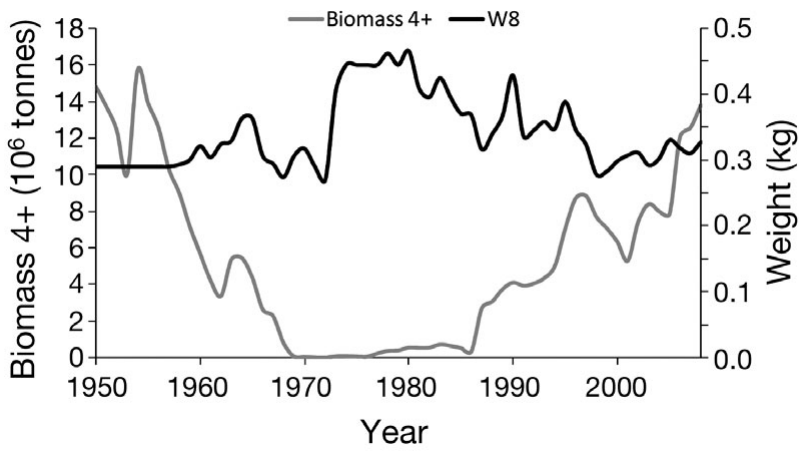

Fig. 4. Clupea harengus. Biomass of age 4+ Norwegian spring spawning (NSS) herring and average weight of age 8 NSS herring (W8). Data taken from ICES (2007)

changes in wintering areas prior to this, and it seems highly plausible that several other wintering areas have been utilised before the period reported here. In addition, other areas may have been utilised during our study period without our knowledge. However, given the frequent surveys by research vessels and extensive fishing activity in Norwegian waters, it seems very unlikely that major wintering areas have remained unreported. Since the 1980s the stock has been monitored closely and the main wintering areas used during the study period are most likely covered in Fig. 1, although wintering areas for minor parts of the stock may have been missed.

Rather than viewing the changes in wintering area as a deterministic process, they are probably more truly seen as a stochastic process where the probability of occurring is governed by the ratio of recruit to repeat spawners. At high ratios it will nearly always happen, at low ratios almost never, and in between it will occur occasionally. The process can be quantified using logistic regression as shown in Fig. 5, which gives the probability of a change in wintering area as a function of the proportion of repeat spawners (age $5+)$ relative to the adult stock abundance (age 4+), based on the time series of data shown in Fig. 2A with 5 changes in wintering area. Note that the proportion of repeat spawners rather than the ratio of recruit to repeat spawners was used in Fig. 5 to allow comparison with the simulation results by Huse et al. (2002). The $50 \%$ probability for a change takes place at a proportion of repeat spawners of 0.18 , which corresponds to a ratio of recruit to repeat spawners of 2.55. Fig. 5 illustrates that although there is a fairly steep decline in the probability of changing wintering area with increasing proportion of repeat spawners, there is also a considerable range where the outcome is uncertain. This is illustrated by the NSS herring abundance time series (Fig. 2A), which shows that there are some years with peaks in the recruit to repeat spawner ratio when changes in wintering area should be expected, but did not take place. In particular this is seen in 1967, 1977 and 2006 (Fig. 2A). These 3 peaks occur 3 to $4 \mathrm{yr}$ after establishment of new wintering areas, and therefore take place with a spawning stock dominated by 7 to $8 \mathrm{yr}$ old cohorts. The low age of the spawning stock in these years might have facilitated the interaction with the recruit spawners. In fact the smallest time difference between changes in wintering area reported here is 7 yr (between 1995 and 2002, Fig. 2A). This could imply that the magnitude of the age and/or size difference between the first-time spawners and the

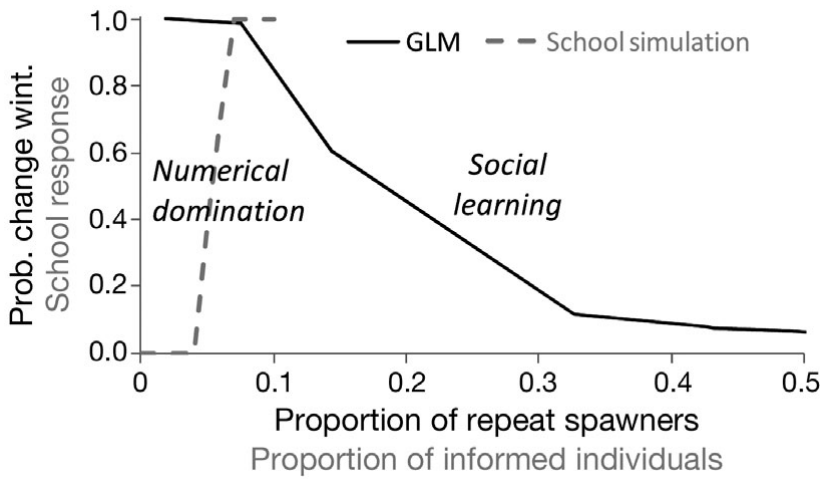

Fig. 5. Predicted probability of change in wintering area (Prob. change wint.) as a function of the proportion of repeat spawners (age 5+) in the spawning stock based on logistic regression and the school response as a function of the proportion of informed individuals from Huse et al. (2002), based on the simulation with 450 individuals. The binomial logistic regression was estimated using the generalized linear model (GLM) function in R (version 2.8.1, R Development Core Team 2008) with the proportion of repeat spawners as the explanatory variable and change in wintering area (or not) as the response 
repeat spawners somehow affects their interaction. Due to the dependence of swimming speed on body length, it may be difficult for small recruits to pursue the larger, older individuals (Slotte 2001). Abundant year classes tend to have a lower than average size at age (Toresen \& Østvedt 2000). However, we did not find a consistent pattern in the weight-at-age time series (Fig. 2B) that would suggest that size is important in determining the changes in wintering area. Nevertheless, there could be differences related to age, size or schooling dynamics that make adoption of traditions more likely to take place between adjacent age groups than if the age span is greater.

Changes in wintering area of North Sea herring have been associated with changes in wind and current directions (Corten 1999), but we found no consistent pattern in temperature related to the changes in wintering area of NSS herring (Fig. 2C) that would suggest consistent changes in environmental conditions associated with the establishment of new wintering areas.

It could be argued that there are other properties of the abundant year classes that make them less likely to mix with the older individuals and that the breaking of tradition is affected by lack of spatial overlap. The degree of spatial overlap between the recruits and older individuals is not completely known, and we have been unable to establish complete time series of the spatial distribution of the NSS stock. The adult herring initiate the migration towards the wintering areas at the end of the summer (Dragesund et al. 1997). Since 1994 there have been surveys in July-August in most years to map the distribution of the herring in the Norwegian Sea (Holst et al. 2004, ICES 2004). In all years with surveys at this time, the herring were distributed close to the Norwegian coast near the Lofoten Islands (between Areas 5 and 6, Fig. 1). This is the area that the juvenile herring enter when leaving the nursery areas in the Barents Sea. There is some interannual variation in the nursery area used by NSS herring (Holst \& Slotte 1998), and there is less knowledge about the initial migration behaviour of juvenile herring that emerge from coastal waters. During the period when the NSS herring stock was in a collapsed state in the 1970s, some cohorts mainly grew up along the Norwegian coast, but in the period before and after the collapse, the Barents Sea has been the dominant nursery area for the stock (Holst \& Slotte 1998). Changes in wintering area have taken place from both nursery grounds.

In summary, our results strongly suggest that the relative scarcity of old herring and thus demography is the critical factor in explaining when new wintering areas are established. Nevertheless, it is best viewed as a stochastic process (Fig. 5) and other factors such as the spatial distribution pattern or age structure of the spawning stock can play a role in certain situations.

\section{Decision making in collective systems}

The simulation study by Huse et al. (2002) explored decision making in schools consisting of experienced and naïve individuals. The simulated individuals optimized their distance to neighbours and matched the movement vectors of neighbouring fish. At a given time a randomly chosen collection of the individuals (experienced individuals) were sent out of the school towards a target area and disregarded the schooling behaviour, while the remaining individuals (naïve) kept using the schooling rules. It was found that when the percentage of experienced individuals was below a threshold of about $4 \%$, there was no response (numerical domination) in the naïve individuals, whereas above $7 \%$, the naïve fish always responded and followed the experienced individuals (Fig. 5). A high proportion of experienced individuals (proportion of repeat spawners or informed individuals) therefore allows social learning to take place, whereas a low proportion of experienced individuals leads to numerical domination and disrupts the social learning (Fig. 5). The simulations support the importance of the abundance ratio of experienced to naïve individuals, or old to recruiting herring, for effective leadership in schools, and illustrate in principle how the interaction between cohorts might lead to adoption of tradition or disruption of migration pattern. In honeybees Apis mellifera, scouts search for and guide the swarm to new nest sites. Studies have estimated that only about $5 \%$ of the bees know the precise location of the new nest site and guide the rest of the swarm there (Seeley et al. 1979). Seeley et al. (1979, p. 107) note that 'Because the ratio of ignorant to informed (scout) bees is so large, it appears important that as many scouts as possible be back at the swarm when lift-off occurs to guide the swarm to the new nest site.' This phenomenon is in many ways similar to our herring case, and the proportion of informed to ignorant is $5 \%$, similar to the school simulation (Fig. 5). This proportion also corresponds to the sharp decrease in the probability of change in wintering area of herring and thus an increase in the likelihood of effective guidance of recruit by repeat spawners (Fig. 5). Numerical domination might be an important phenomenon to animal groups in general, and the similarity of these ratios is intriguing. However, it remains inconclusive whether the similarity has some deeper ecological meaning.

In another simulation study, Couzin et al. (2005) found that the proportion of experienced individuals (or demonstrators) required to exert effective leader- 
ship in a school decreased as group size rose, while Huse et al. (2002) found leadership to be dependent on a constant proportion of demonstrators. The data on NSS herring show that changes in migration pattern can occur over a large span in absolute number of experienced individuals in the stock, but never at a ratio below 1 of recruits to experienced individuals (Figs. 2A \& 5). The recent changes in migration pattern (1995 and 2002) took place with a population of experienced individuals of about 15 billion individuals (ICES 2007), while in 1963 and 1973 the number of experienced individuals was estimated to be 8 and 0.03 billion individuals, respectively. Changes in migration pattern thus take place at a wide range of population sizes. Although the field and simulation studies are of different scales, this supports the simulation result that it is the proportion of experienced individuals in the group rather than any absolute number that is important for the collective dynamics of the group.

Schools may interact in a related manner as individuals within schools. Using long ranging sonar it has been shown that rapid transition from disordered to highly synchronized behaviour occurs as herring density reaches a critical value, and that organized group migration occurs after this transition, possibly initiated by a small set of leaders (Makris et al. 2009). These results are promising, but more work is clearly needed in addressing mesoscale interactions between schools, in particular in relation to the role that olfaction, hearing and other senses have in the interaction.

\section{The adaptive value of herring migrations}

Even though the migration displacement estimates are intended to represent the old part of the spawning stock which makes the longest migrations (Nøttestad et al. 1999), the actual swimming distances are likely to be quite a bit higher due to the fact that fish schools often do not maintain a straight heading. Misund et al. (1997) estimated the velocity to be about $18 \%$ of the swimming speed during the westward migration of the NSS herring stock in April. But the directionality of the migration is likely to be higher during migrations to the wintering area or to the spawning areas (Nøttestad et al. 1996). The spawning migration displacement is fairly well estimated, but the feeding migrations are in some cases much longer than given in the estimates since it is difficult to provide point estimates for the feeding distribution. Nevertheless, this analysis shows that there are considerable differences between the different periods with regards to migration distance. The energy expenditure is generally 3 times higher during the spawning migration than during wintering (Slotte 1999), which indicates that migration distance is more critical for energy expenditure than differences in wintering temperature. However, although high wintering temperature will result in relatively high metabolic costs over the winter, high temperature may have positive effects on maturation.

Our results show that NSS herring presently spend the winter in energetically sub-optimal habitats associated with staying in warmer waters and performing longer migrations than in previous periods. However, since the entire stock congregates in 1 or 2 areas, such a seemingly sub-optimal strategy has small consequences for individual fitness, which is defined relative to the other individuals in the population (Krebs \& Davies 1997). Repeat homing can have some clear disadvantages related to energy expenditure during wintering and migration. However, it may increase survival through the winter. Furthermore, aggregating in one area provides predictability and ensures that herring that have been feeding in different parts of the sea meet up with other schools at the wintering ground. This seems to be a key issue in the development of the repeat homing strategy (McQuinn 1997). The establishment of new wintering areas initiated by abundant first-time spawners can alter the migration pattern of the stock substantially. The changes may in some cases be maladaptive with regards to habitat characteristics and migration pattern, but in other cases beneficial by breaking up a pattern maintained by the old fish that may be poorly adapted to the existing environmental conditions. Rather than being strictly optimized, our findings thus suggest that the establishment of wintering areas is at the mercy of general school cohesion mechanisms and numerical domination. The herring therefore appear to have a robust and conservative rather than optimal habitat selection strategy, reflecting these fish are adaptation executers and not fitness maximisers (Wright 1994).

The migration triangle, which conceptually describes the movement of stocks during different life stages, has had a great impact of the understanding of fish migrations within the field of fisheries biology (Harden Jones 1968). In contrast, behavioural ecology (Krebs \& Davies 1997) focuses strongly on individual fitness maximization as the explanation for the spatial ecology of fish and other animals. Our results illustrate that there is need for a unification of these disciplines with the field of complex adaptive systems (Camazine et al. 2001) if we are to understand the spatial ecology of migratory fish stocks.

Acknowledgements. We thank A. Slotte, R. Nash and 3 anonymous reviewers for valuable comments on a previous version of this paper and G. Dingsør for help on the statistical analyses. The research programme Havet og Kysten of the Research Council of Norway is acknowledged for financial support through the INFERNO project. 


\section{LITERATURE CITED}

Brown C, Laland KN (2003) Social learning in fishes: a review. Fish Fish 4:280-288

Camazine S, Deneubourg JL, Franks NR, Sneyd J, Theraulaz G, Bonabeau E (2001) Self-organization in biological systems. Princeton University Press, Princeton, NJ

Corten A (1999) A proposed mechanism for the Bohuslän herring periods. ICES J Mar Sci 56:207-220

Corten A (2001a) Northern distribution of North Sea herring as a response to high water temperatures and/or low food abundance. Fish Res 50:189-204

Corten A (2001b) The role of 'conservatism' in herring migrations. Rev Fish Biol Fish 11:339-361

Couzin ID, Krause J, Franks NR, Levin SA (2005) Effective leadership and decision-making in animal groups on the move. Nature 433:513-516

Devold F (1968) The formation and the disappearance of a stock unit of Norwegian herring. Fiskeridir Skr Ser Havunders 15:1-22

Dragesund O, Johannessen A, Ulltang $\varnothing$ (1997) Variation in migration and abundance of Norwegian spring spawning herring (Clupea harengus L.). Sarsia 82:97-105

Fernö A, Pitcher TJ, Melle W, Nøttestad L, Mackinson S, Hollingworth C, Misund OA (1998) The challenge of the herring in the Norwegian Sea: making optimal collective spatial decisions. Sarsia 83:149-167

Foote K, Ostrowski M, Røttingen I, Engås A, Hansen KA, Hauge KH, Skeide R, Slotte A, Torgersen Ø (1996) Acoustic abundance estimation of the stock of Norwegian spring spawning herring, winter 1995-1996. ICES CM 1996/H:33. ICES, Copenhagen

Foote KG, Ostrowski M, Røttingen I, Slotte A (1997) Abundance estimation of Norwegian spring spawning herring wintering in the Vestfjord system, December 1996. ICES CM 1997/FF:13. ICES, Copenhagen

Fretwell SD, Lucas HJJ (1969) On territorial behaviour and other factors influencing habitat distribution in birds. I. Theoretical development. Acta Biotheor 19:16-36

Harden Jones FR (1968) Fish migration. Edward Arnold, London

Helfman GS, Schultz ET (1984) Social transmission of behavioral traditions in a coral reef fish. Anim Behav 32:379-384

Holst JC, Slotte A (1998) Effects of juvenile nursery on geographic spawning distribution in Norwegian springspawning herring (Clupea harengus L.). ICES J Mar Sci 55:987-996

Holst JC, Dragesund O, Hamre J, Misund OA, Østvedt OJ (2002) Fifty years of herring migrations in the Norwegian Sea. ICES Mar Sci Symp 215:352-360

Holst JC, Røttingen I, Melle W (2004) The herring. In: Skjoldal HR (ed) The Norwegian Sea ecosystem. Tapir Academic Press, Trondheim, p 203-226

Huse G, Railsback SF, Fernö A (2002) Modelling changes in migration pattern of herring: collective behaviour and numerical domination. J Fish Biol 60:571-582

ICES (1997) Report of the ICES planning group on surveys on pelagic fish in the Norwegian Sea (PGSPEN). ICES CM 1997/H:3. ICES, Copenhagen

ICES (2004) Report of the planning group on Northeast Atlantic pelagic ecosystem surveys (PGNAPES). ICES CM 2004/D:07. ICES, Copenhagen

ICES (2007) Report of the working group on northern pelagic and blue whiting fisheries (WGNPBW). ICES CM 2007/ACFM:29. ICES, Copenhagen

Jacobsen JA, Gudmundsdottir A, Heino M, Holst JC and others (2002) Report of the planning group on surveys on pelagic fish in the Norwegian Sea. ICES CM 2002/D:07. ICES, Copenhagen

Krause J, Bumann D, Todt D (1992) Relationship between the position preference and nutritional state of individuals in schools of juvenile roach (Rutilus rutilus). Behav Ecol Sociobiol 30:177-180

Krebs JR, Davies NB (eds) (1997) Behavioural ecology: an evolutionary approach. Blackwell Scientific Publications, Oxford

Lohmann KJ, Lohmann CMF (1996) Orientation and open-sea navigation in sea turtles. J Exp Biol 199:73-81

Makris NC, Ratilal P, Jagannathan S, Gong Z and others (2009) Critical population density triggers rapid formation of vast oceanic fish shoals. Science 323:1734-1737

Mangel M, Clark CW (1988) Dynamic modelling in behavioral ecology. Princeton University Press, Princeton, NJ

McQuinn IH (1997) Metapopulations and the Atlantic herring. Rev Fish Biol Fish 7:297-329

Misund OA, Melle W, Fernö A (1997) Migration behaviour of Norwegian spring spawning herring when entering the cold front in the Norwegian Sea. Sarsia 82:107-112

Misund OA, Vilhjalmsson H, Jakupsstovu SHI, Rottingen I and others (1998) Distribution, migration and abundance of Norwegian spring spawning herring in relation to the temperature and zooplankton biomass in the Norwegian Sea as recorded by coordinated surveys in spring and summer 1996. Sarsia 83:117-127

Nøttestad L, Aksland M, Beltestad A, Fernö A, Johannessen A, Misund OA (1996) Schooling dynamics of Norwegian spring spawning herring (Clupea harengus L.) in a coastal spawning area. Sarsia 80:277-284

$>$ Nøttestad L, Giske J, Holst JC, Huse G (1999) A length-based hypothesis for feeding migrations in pelagic fish. Can J Fish Aquat Sci 56:26-34

Pitcher TJ, Parrish JK (1993) Functions of shoaling behaviour in teleosts. In: Pitcher TJ (ed) Behaviour of teleost fishes. Chapman \& Hall, London, p 363-439

Pitcher TJ, Magurran AE, Winfield IJ (1982) Fish in larger shoals find food faster. Behav Ecol Sociobiol 10:149-151

R Development Core Team (2008) R: a language and environment for statistical computing. R Foundation for Statistical Computing, Vienna

Reebs SG (2000) Can a minority of informed leaders determine the foraging movements of a fish shoal? Anim Behav 59:403-409

Roff DA (1992) The evolution of life histories: theory and analysis. Chapman \& Hall, New York, NY

Romey WL (1996) Individual differences make a difference in the trajectories of simulated schools of fish. Ecol Model 92:65-77

Røttingen I (1990) A review of variability in the distribution and abundance of Norwegian spring spawning herring and Barents Sea capelin. Polar Res 8:33-42

Røttingen I (1992) New migration routes of Norwegian spring spawning herring. ICES CM 1992/H:18. ICES, Copenhagen

Sætre R, Toresen R, Anker-Nilssen T (2002) Factors affecting the recruitment variability of the Norwegian springspawning herring (Clupea harengus L.). ICES J Mar Sci 59:725-736

Seeley TD, Morse RA, Visscher PK (1979) The natural history of the flight of honey bee swarms. Psyche 86:103-113

Sinnott RW (1984) Virtues of the Haversine. Sky Telescope 68:159

Slotte A (1999) Differential utilization of energy during wintering and spawning migration in Norwegian springspawning herring. J Fish Biol 54:338-355 
Slotte A (2001) Factors influencing location and time of spawning in Norwegian spring-spawning herring: an evaluation of different hypotheses. In: Herring: expectations for a new millennium. Alaska Sea Grant College Program, Anchorage, AK, p 255-278

Stearns SC (1992) The evolution of life histories. Oxford University Press, Oxford

Sutherland WJ (1996) From individual behaviour to population ecology. Oxford University Press, Oxford

Tereshchenko VV (1996) Seasonal and year-to-year variations of temperature and salinity along the Kola meridian

Editorial responsibility: Hans Heinrich Janssen, Oldendorf/Luhe, Germany transect. ICES CM 1996/C:11. ICES, Copenhagen

Toresen R, Østvedt OJ (2000) Variation in abundance of Norwegian spring-spawning herring (Clupea harengus, Clupeidae) throughout the 20th century and the influence of climatic fluctuations. Fish Fish 1:231-256

Videler JJ (1993) Fish swimming. Chapman \& Hall, London > Walker MM, Diebel CE, Haugh CV, Pankhurst PM, Montgomery JC, Green CR (1997) Structure and function of the vertebrate magnetic sense. Nature 390:371-376

Wright R (1994) The moral animal. Why we are the way we are. Abacus, London

Submitted: July 2, 2009; Accepted: April 12, 2010

Proofs received from author(s): June 1, 2010 